\title{
Closure of radial forearm free flap donor-site defect with proportional local full-thickness skin graft: case series study of a new design
}

\author{
Yoon-Sic Han, Ho Lee \\ Department of Oral and Maxillofacial Surgery, Section of Dentistry, SMG-SNU Boramae Medical Center, Seoul, Korea
}

\begin{abstract}
J Korean Assoc Oral Maxillofac Surg 2021;47:427-431)
Objectives: The aim of this study was to describe a simple, convenient, and reliable new technique using local full-thickness skin graft (FTSG) for skin coverage of a donor-site defect of the radial forearm free flap (RFFF).

Patients and Methods: Between April 2016 and April 2021, five patients with oral squamous cell carcinoma underwent mass resection combined with RFFF reconstruction. After RFFF harvesting, donor-site defects were restored by proportional local FTSG.

Results: The donor-site defects ranged in size from 24 to $41.25 \mathrm{~cm}^{2}$, with a mean of $33.05 \mathrm{~cm}^{2}$. Good or acceptable esthetic outcomes were obtained in all five patients. There was no dehiscence, skin necrosis, wound infection, or severe scarring at the graft site through the end of the postoperative follow-up period, and no patient had any specific functional complaint.

Conclusion: The proportional local FTSG showed promising results for skin coverage of the donor-site defect of the RFFF. This technique could decrease the need for skin grafts from other sites.
\end{abstract}

Key words: Radial forearm free flap, Local full-thickness skin graft, Donor site morbidity

[paper submitted 2021. 7. 29 / accepted 2021. 9. 6]

\section{Introduction}

The radial forearm free flap (RFFF) is the most popular flap for intraoral reconstruction. The technique was first described in $1981^{1}$. Many methods have been reported for skin coverage of the donor-site defect, including split-thickness skin graft (STSG), full-thickness skin graft (FTSG), meshed FTSG, acellular dermal matrix, and porcine collagen membrane $^{2-4}$.

Several researchers have described local FTSG techniques for repair of RFFF defects and have demonstrated their usefulness $^{5-8}$. If too much skin is taken from the forearm site, it can lead to failure of primary closure. Because the forearm gradually narrows from the cephalad to the caudad region,

\section{Ho Lee}

Department of Oral and Maxillofacial Surgery, Section of Dentistry, SMGSNU Boramae Medical Center, 20 Boramae-ro 5-gil, Dongjak-gu, Seoul 07061, Korea

TEL: $+82-2-870-2496$

E-mail:neo0224@gmail.com

ORCID: https://orcid.org/0000-0002-0413-2954

(c) This is an open-access article distributed under the terms of the Creative Commons Attribution Non-Commercial License (http://creativecommons.org/ licenses/by-nc/4.0/), which permits unrestricted non-commercial use, distribution, and reproduction in any medium, provided the original work is properly cited.

Copyright (C) 2021 The Korean Association of Oral and Maxillofacial Surgeons. full thickness skin is harvested more readily from the cephalad area.

Considering the esthetics when using FTSG, it is important to collect only the necessary amount of skin and to achieve primary closure after full-thickness skin harvesting. We describe a simple and convenient new technique using local FTSG based on the proportional geometric concept.

\section{Patients and Methods}

In the period between April 2016 and April 2021, five patients with oral squamous cell carcinoma underwent mass resection combined with RFFF reconstruction at the Department of Oral and Maxillofacial Surgery, SMG-SNU Boramae Medical Center (Seoul, Korea). After RFFF harvesting, donor-site defects were restored by FTSG. The study was approved by the Institutional Review Board of the SMG-SNU Boramae Medical Center (IRB No. 07-2017-19). The present study was designed in accordance with the Declaration of Helsinki. 


\section{Surgical technique}

The RFFF is designed by outlining the path of the radial artery and cephalic vein. Before elevating the RFFF, the local FTSG is designed according to the long axis of the pedicle. Two oval skin islands $\left(\mathrm{S}_{1}\right.$ and $\left.\mathrm{S}_{2}\right)$ are marked, and the distant one $\left(\mathrm{S}_{2}\right)$ is divided into two semilunar skin islands $\left(\mathrm{S}_{2 \mathrm{a}}\right.$ and $\mathrm{S}_{2 \mathrm{~b}}$ ).(Fig. 1. A) The RFFF and each skin island are equal in horizontal length $(B)$, while the vertical width of the skin islands is proportional to the width of the forearm at the central point of each skin island $\left(\alpha_{1}\right.$ and $\left.\alpha_{2}\right)$. The vertical width of the $\operatorname{RFFF}(A)$ is equal to the sum of the vertical widths of the skin islands $\left(a_{1}\right.$ and $\left.a_{2}\right)$.(Fig. 1 . B)

\section{Formulas:}

$$
\begin{aligned}
& A=a_{1}+a_{2}, a_{1}=\alpha_{1} x, a_{2}=\alpha_{2} x \\
& A=\left(\alpha_{1}+\alpha_{2}\right) x, x=\frac{\mathrm{A}}{\left(\alpha_{1}+\alpha_{2}\right)} \\
& a_{1}=\frac{A_{\alpha 1}}{\left(\alpha_{1}+\alpha_{2}\right)}, a_{2}=\frac{A_{\alpha 2}}{\left(\alpha_{1}+\alpha_{2}\right)}
\end{aligned}
$$

After harvesting the RFFF, $\mathrm{S}_{1}$ is grafted onto the central area of the donor-site defect, while $S_{2 a}$ and $S_{2 b}$ are grafted onto the upper and lower sides of $\mathrm{S}_{1}$. (Fig. 1. C)

\section{Clinical case}

A 58-year-old male complained of a large mass in the mouth, for which multiple biopsies were performed. The diagnosis was squamous cell carcinoma of the palatoglossal arch. Mass removal and reconstruction surgery using RFFF were conducted under general anesthesia. The size of the RFFF was $75(B) \mathrm{mm} \times 55(A) \mathrm{mm}$. The width of the forearm at the center of each skin island was $65\left(\alpha_{1}\right) \mathrm{mm}$ and $85\left(\alpha_{2}\right)$ $\mathrm{mm}$, respectively. According to the formula, $a_{1}$ and $a_{2}$ were $23.8 \mathrm{~mm}$ and $31.2 \mathrm{~mm}$, respectively. One oval skin island (75 $\mathrm{mm} \times 24 \mathrm{~mm})$ and two semicircular skin islands $(75 \mathrm{~mm} \times 15.5$ $\mathrm{mm}$ ) were harvested for FTSG.(Fig. 2)
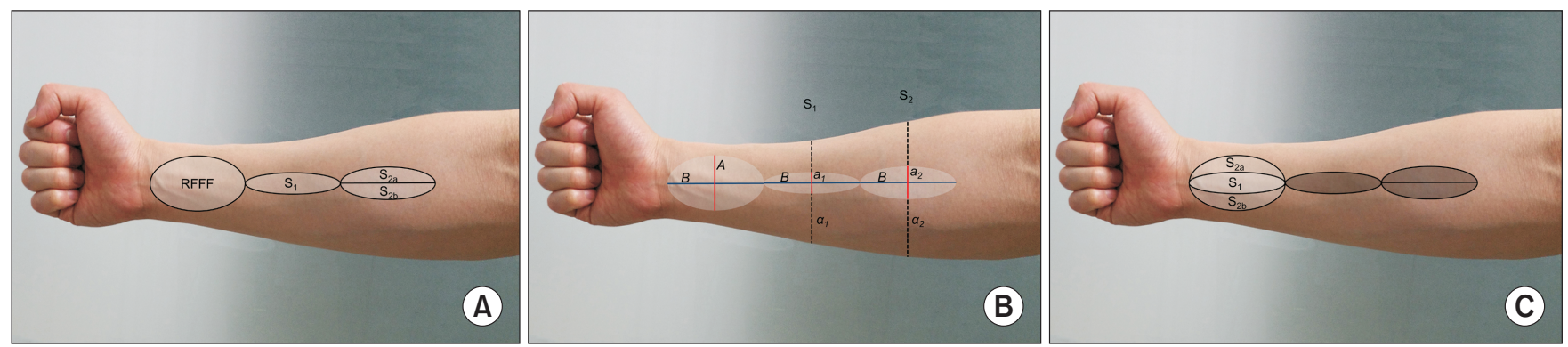

Fig. 1. Diagram of a proportional local full-thickness skin graft. A. One oval and two semilunar skin islands were designed to cover the donor site defect. B. Design of full-thickness skin island. The vertical length of $S_{2}$ is proportionally longer than that of $S_{1}$. C. $S_{1}$ is grafted at the center, and $\mathrm{S}_{2 \mathrm{a}}$ and $\mathrm{S}_{2 \mathrm{~b}}$ are grafted on the upper and lower sides, respectively. (RFFF: radial forearm free flap)

Yoon-Sic Han et al: Closure of radial forearm free flap donor-site defect with proportional local full-thickness skin graft: case series study of a new design. J Korean Assoc Oral Maxillofac Surg 2021
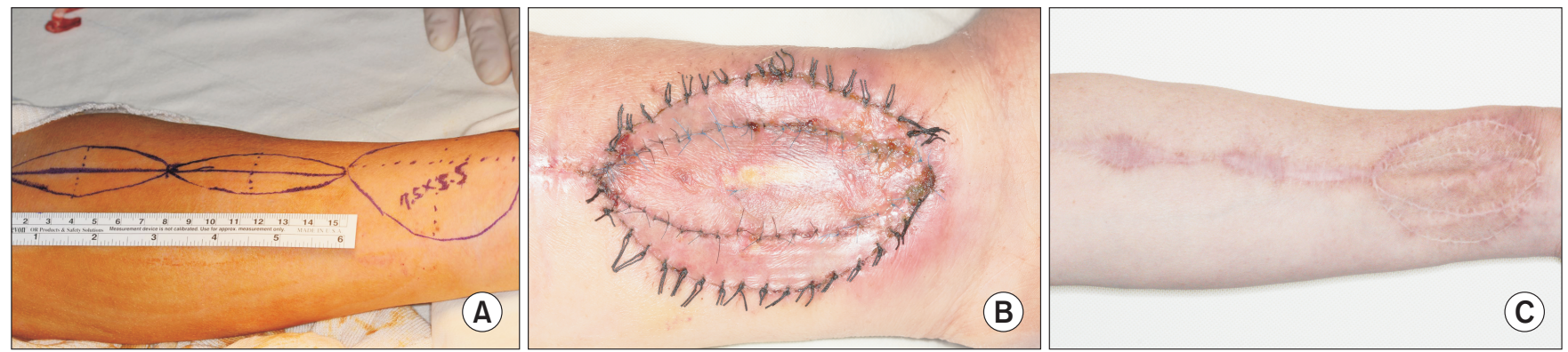

Fig. 2. Design and postoperative appearance of the radial forearm free flap (RFFF) donor-site restoration. A. Preoperative design of the RFFF and full-thickness skin islands for closure of the defect. B. Postoperative two weeks after removal of the tie-over bolus dressing. C. Postoperative healing after 13 months.

Yoon-Sic Han et al: Closure of radial forearm free flap donor-site defect with proportional local full-thickness skin graft: case series study of a new design. J Korean Assoc Oral Maxillofac Surg 2021 
Table 1. Summary of patients and full-thickness skin graft (FTSG) data

\begin{tabular}{|c|c|c|c|c|c|c|c|c|c|c|}
\hline $\begin{array}{c}\text { Patient } \\
\text { No. }\end{array}$ & Age (yr) & Sex & Diagnosis & $\begin{array}{c}\text { Site of } \\
\text { oral cancer }\end{array}$ & $\begin{array}{c}\text { Size of } \\
\text { FTSG }\left(\mathrm{cm}^{2}\right)\end{array}$ & $\begin{array}{l}\text { Length of } \\
A(\mathrm{~mm})\end{array}$ & $\begin{array}{l}\text { Length of } \\
a_{1}(\mathrm{~mm})\end{array}$ & $\begin{array}{c}\text { Length of } \\
a_{2}(\mathrm{~mm})\end{array}$ & $\begin{array}{c}\text { Length of } \\
B(\mathrm{~mm})\end{array}$ & $\begin{array}{c}\text { Follow-up } \\
\text { period (mo) }\end{array}$ \\
\hline 1 & 68 & Female & SCC & Tongue & 24 & 40 & 18 & 22 & 60 & 13 \\
\hline 2 & 58 & Male & SCC & Palatoglossal arch & 41.25 & 55 & 24 & 31 & 75 & 51 \\
\hline 3 & 75 & Male & SCC & Maxillary gingiva & 35 & 50 & 21 & 29 & 70 & 52 \\
\hline 4 & 81 & Male & SCC & Mandibular gingiva & 35 & 50 & 22 & 28 & 70 & 47 \\
\hline 5 & 64 & Male & SCC & Palatoglossal arch & 30 & 50 & 22 & 28 & 60 & 3 \\
\hline
\end{tabular}

(SCC: squamous cell carcinoma, $A$ : vertical width of the radial forearm free flap [RFFF], $a_{1}$ and $a_{2}$ : vertical width of each skin island, $B$ : horizontal width of the RFFF)

Yoon-Sic Han et al: Closure of radial forearm free flap donor-site defect with proportional local full-thickness skin graft: case series study of a new design. J Korean Assoc Oral Maxillofac Surg 2021

\section{Results}

Donor-site defects in four consecutive patients (three male patients) who underwent reconstruction with the RFFF were covered with a proportional local FTSG.(Table 1) The mean age of the study group was 69.2 years. The donor-site defects ranged in size from 24 to $41.25 \mathrm{~cm}^{2}$, with a mean of 33.05 $\mathrm{cm}^{2}(60 \mathrm{~mm} \times 40 \mathrm{~mm} ; 75 \mathrm{~mm} \times 55 \mathrm{~mm} ; 70 \mathrm{~mm} \times 50 \mathrm{~mm} ; 70$ $\mathrm{mm} \times 50 \mathrm{~mm}$; and $60 \mathrm{~mm} \times 50 \mathrm{~mm}$ ). Good or acceptable esthetic outcomes were obtained in all five patients. There was no dehiscence, skin necrosis, wound infection, or severe scarring at the graft site at the end of the postoperative follow-up period, and no patient had any specific functional complaint.

\section{Discussion}

RFFF is a very useful flap for reconstruction of head and neck defects by virtue of its advantages including relative ease of harvesting, adequate bulkiness, good pliability, and long vascular pedicle 9 . Despite the reputation of the flap itself, there has been a lack of consensus with regard to the method of restoring RFFF donor sites. As such, the method has depended on the preference and experience of individual surgeons, and various methods have been introduced ${ }^{10}$. Among these, STSGs have been used most commonly due to the strengths of simple harvesting methods and acceptable functional outcomes ${ }^{3}$. However, there are functional problems, such as delayed healing, partial graft loss, exposure of flexor tendon, persistent wrist stiffness, cold intolerance or reduced hand strength associated with STSG, as well as esthetic problems related to scar infection, skin tension, or hypertrophic scar formation ${ }^{11,12}$. In contrast, FTSG is known to supply a thicker base than STSG, averting wound breakdown and facilitating superior cosmetic results ${ }^{13,14}$. In this report, we propose a new method for repairing the RFFF donor site using FTSG from adjacent skin.

There have been several studies in which FTSG has been performed with the abdomen or opposite forearm as the donor site. However, this method requires a second surgical site, which is a disadvantage ${ }^{9}$. Therefore, Kaltman et al. ${ }^{10}$ have reported FTSG from the ipsilateral upper inner arm, eliminating the requirement for a second surgical site. These authors have reported good outcomes in terms of color match and inconspicuous scar. Our technique also eliminates the need for additional wound formation using the skin area that is to be dissected for harvest of the vascular pedicle of the RFFF and showed good aesthetic outcomes. There have also been reports of good results in terms of skin quality, rapid healing, and good functional outcomes when using local fasciocutaneous transposition flaps as an alternative to nonvascularized free flaps ${ }^{14}$. However, these flaps required extensive dissection, leading to sensory loss and chronic lymphedema ${ }^{3}$.

Shiba et al. ${ }^{15}$ devised a larger FTSG that could cover not only the RFFF donor site, but also the distal portion of the FTSG donor site ${ }^{16}$. They executed a V-Y primary closure at the proximal portion of the FTSG donor site. However, since the triangular FTSG replaced the (essentially) rectangular RFFF donor site, excessive traction at the edges of the middle portion of the repair became a concern, and multiple small slits were needed to distribute tension in the FTSG and prevent fluid collection under the graft due to the relatively large area. Furthermore, the area for tie-over dressing became wider than with the normal FTSG, which could have increased the risk of wound breakdown. Our FTSG replicates the size of the RFFF size, and the design is less complex. Finally, González-García et al. ${ }^{13}$ have reported an FTSG using four 
separate skin triangles adjacent to the RFFF donor site, which is similar to our technique. However, because it considers the difference in distal and proximal forearm widths, our design might be more favorable for distributing the tension of primary closure at the distal side of the donor site. In fact, our patients have shown good healing without compartment syndrome, wound dehiscence, necrosis, or hypertrophic scarring.

In this study, we introduced a new method for repair of the RFFF donor site using an adjacent local FTSG designed with proportional geometric parameters. This method was relatively simple in construction and eliminated the need for additional donor sites such as the abdomen, groin, or thigh, and the advantageous tension distribution led to good healing without major scarring or complications.

\section{Conclusion}

The present study shows successful skin graft of a forearm defect while reducing donor site morbidity. By achieving appropriate skin color, texture, and high patient satisfaction, this new technique is concluded to be a viable option to replace STSG. Although the number of patients is small, these preliminary results are satisfying and additional studies should be completed with a greater number of cases.

\section{ORCID}

Yoon-Sic Han, https://orcid.org/0000-0001-8060-5330

Ho Lee, https://orcid.org/0000-0002-0413-2954

\section{Authors' Contributions}

Y.S.H. organized the survey, designed the study, treated the patients, and wrote the manuscript. H.L. participated in the study design and coordination, and helped to draft the manuscript. All authors read and approved the final manuscript.

\section{Ethics Approval and Consent to Participate}

The study was approved by the Institutional Review Board of the SMG-SNU Boramae Medical Center (IRB No. 072017-19). The present study was designed in accordance with the Declaration of Helsinki, and written informed consent was obtained from all patients.

\section{Conflict of Interest}

No potential conflict of interest relevant to this article was reported.

\section{References}

1. Yang GF, Chen PJ, Gao YZ, Liu XY, Li J, Jiang SX, et al. Forearm free skin flap transplantation: a report of 56 cases. 1981 Br J Plast Surg 1997;50:162-5. https://doi.org/10.1016/s00071226(97)91363-1

2. Sinha UK, Shih C, Chang K, Rice DH. Use of AlloDerm for coverage of radial forearm free flap donor site. Laryngoscope 2002;112: 230-4. https://doi.org/10.1097/00005537-200202000-00006

3. Byun SH, Ahn KM, Kim SM, Lee JH. Functional and cosmetic outcome after closure of radial forearm free flap donor defect with porcine collagen membrane. J Craniomaxillofac Surg 2016;44:52732. https://doi.org/10.1016/j.jcms.2016.02.013

4. Karimi A, Mahy P, Reychler H. Closure of radial forearm free flap donor site defect with a local meshed full-thickness skin graft: a retrospective study of an original technique. J Craniomaxillofac Surg 2007;35:369-73. https://doi.org/10.1016/j.jcms.2007.07.004

5. Kim SM, Park JM, Yang HJ, Myoung H, Lee SK, Lee JH. Aesthetic closure of the donor site of a radial forearm free flap with two local curved skin grafts. J Plast Surg Hand Surg 2016;50:1846. https://doi.org/10.3109/2000656X.2016.1147738

6. Hanna TC, McKenzie WS, Holmes JD. Full-thickness skin graft from the neck for coverage of the radial forearm free flap donor site. J Oral Maxillofac Surg 2014;72:2054-9. https://doi. org/10.1016/j.joms.2014.05.015

7. Lane JC, Swan MC, Cassell OC. Closure of the radial forearm donor site using a local hatchet flap: analysis of 45 consecutive cases. Ann Plast Surg 2013;70:308-12. https://doi.org/10.1097/ SAP.0b013e3182321ba0

8. Moreno-Sánchez M, González-García R, Ruiz-Laza L, Manzano Solo de Zaldívar D, Moreno-García C, Monje F. Closure of the radial forearm free flap donor site using the combined local triangular full-thickness skin graft. J Oral Maxillofac Surg 2016;74:20411. https://doi.org/10.1016/j.joms.2015.08.003

9. González-García R, Rodríguez-Campo FJ, Naval-Gías L, SastrePérez J, Muñoz-Guerra MF, Usandizaga JL, et al. Radial forearm free flap for reconstruction of the oral cavity: clinical experience in 55 cases. Oral Surg Oral Med Oral Pathol Oral Radiol Endod 2007; 104:29-37. https://doi.org/10.1016/j.tripleo.2006.09.026

10. Kaltman JM, McClure SA, Lopez EA, Pedroletti F. Closure of the radial forearm free flap donor site defect with a full-thickness skin graft from the inner arm: a preferred technique. J Oral Maxillofac Surg 2012;70:1459-63. https://doi.org/10.1016/j.joms.2011.05.003

11. Ho T, Couch M, Carson K, Schimberg A, Manley K, Byrne PJ. Radial forearm free flap donor site outcomes comparison by closure methods. Otolaryngol Head Neck Surg 2006;134:309-15. https:// doi.org/10.1016/j.otohns.2005.09.019

12. Lutz BS, Wei FC, Chang SC, Yang KH, Chen IH. Donor site morbidity after suprafascial elevation of the radial forearm flap: a prospective study in 95 consecutive cases. Plast Reconstr Surg 1999; 103:132-7. https://doi.org/10.1097/00006534-199901000-00021

13. González-García R, Ruiz-Laza L, Manzano D, Moreno C, Maestre $\mathrm{O}$, Serrano $\mathrm{H}$, et al. Combined local triangular full-thickness skin graft for the closure of the radial forearm free flap donor site: a new technique. J Oral Maxillofac Surg 2009;67:1562-7. https://doi. org/10.1016/j.joms.2009.03.010

14. Bashir MA, Fung V, Kernohan MD, Ragbir M, Ahmed OA. "Zplasty" modification of ulnar-based fasciocutaneous flap for closure of the radial forearm flap donor defect. Ann Plast Surg 2010;64:22- 
3. https://doi.org/10.1097/SAP.0b013e3181a13d8d

15. Shiba K, Iida $Y$, Numata T. Ipsilateral full-thickness forearm skin graft for covering the radial forearm flap donor site. Laryngoscope 2003;113:1043-6. https://doi.org/10.1097/00005537-20030600000023

16. Giordano L, Bondi S, Ferrario F, Fabiano B, Bussi M. Radial forearm free flap surgery: a modified skin-closure technique improving donor-site aesthetic appearance. Acta Otorhinolaryngol Ital 2012; $32: 158-63$.
How to cite this article: Han YS, Lee H. Closure of radial forearm free flap donor-site defect with proportional local full-thickness skin graft: case series study of a new design. J Korean Assoc Oral Maxillofac Surg 2021;47:427-431. https://doi.org/10.5125/ jkaoms.2021.47.6.427 